Recherches politiques internationales sur les espaces issus de l'histoire et de la colonisation portugaises

XVII(2) | 2018

Lusotopie. Concepts et pratiques

\title{
A Fundação Eduardo dos Santos (FESA). A propósito da "investida" da sociedade civil pelo poder angolano
}

\author{
Nota introdutória por Michel Cahen \\ La Fondation Eduardo dos Santos (FESA). À propos de l' investissement » de la \\ société civile par le pouvoir angolais \\ The Eduardo dos Santos Foundation. Or, How Angola's Regime is Taking Over \\ Civil Society
}

\section{Christine Messiant}

Tradutor. Filomena Vieira Embaló

\section{OpenEdition}

Journals

Edição electrónica

URL: https://journals.openedition.org/lusotopie/3403

ISSN: 1768-3084

Editora

Idemec - UMR 7307

Edição impressa

Data de publição: 1 dezembro 2018

Paginação: 331-355

ISSN: 1257-0273

\section{Refêrencia eletrónica}

Christine Messiant, «A Fundação Eduardo dos Santos (FESA). A propósito da "investida" da sociedade civil pelo poder angolano», Lusotopie [Online], XVII(2) | 2018, posto online no dia 01 julho 2021, consultado o 02 outubro 2021. URL: http://journals.openedition.org/lusotopie/3403

Este documento foi criado de forma automática no dia 2 outubro 2021.

Lusotopie 


\title{
A Fundação Eduardo dos Santos (FESA). A propósito da "investida" da sociedade civil pelo poder angolano
}

\author{
Nota introdutória por Michel Cahen \\ La Fondation Eduardo dos Santos (FESA). À propos de l'« investissement » de la \\ société civile par le pouvoir angolais \\ The Eduardo dos Santos Foundation. Or, How Angola's Regime is Taking Over \\ Civil Society
}

Christine Messiant

Tradução : Filomena Vieira Embaló

\section{NOTA DO EDITOR}

Tradução do texto francês por Filomena Vieira Embaló (Paris), revisão por Angela Lazagna (Campinas, Unicamp).

Christine Messiant, falecida aos 58 anos de idade em 3 de Janeiro de 2006, era uma grande especialista em sociologia política e histórica de Angola, tanto do seu período colonial, como independente. Messiant nos deixou uma imensa obra sobre a Angola contemporânea, composta, sobretudo, por artigos em francês, bem como pela publicação tardia (2006), posterior a sua morte, da sua tese de doutorado, orientada por Georges Balandier e defendida em 1983. Mais tarde, Brigitte Lachartre e Michel Cahen editam uma coletânea de parte dos seus principais artigos sobre Angola (2008-2009). 
Marxista e trotskista, sempre crítica ao regime do partido único - mais tarde hegemônico - do MPLA (Movimento Popular de Libertação de Angola), Messiant desenvolveu nomeadamente uma análise contundente do neopatrimonialismo do poder do presidente José Eduardo dos Santos, construído na e pela guerra civil. Um artigo emblemático, onde desenvolve sua análise acerca do neopatrimonialismo, tem como objeto a Fundação José Eduardo dos Santos (FESA). Criada ao 29 março de 1996, a FESA, instituição batizada com o nome do presidente de Angola que ocupava tal posto desde 20 de setembro de 1979, logo após a morte de Agostinho Neto (primeiro presidente da Angola independente), é, com efeito, um exemplo fascinante da "oficialização" do patrimonialismo em um Estado africano. As receitas desta fundação, com representações no exterior (Brasil, Canadá), provinham, particularmente, de doações de empresas estrangeiras desejosas de obter contratos no país, isto é, de um volume de dinheiro que, em um quadro político-legal distinto, seria incorporado aos tributos arrecadados pelo Estado e ao orçamento oficial da República. Desta maneira, era em nome da pessoa do Presidente, e não da República, que a FESA financiava obras sociais, desportivas ou acadêmicas, todas, naturalmente, inauguradas pelo Presidente ou em seu nome, sobretudo no "auge" das suas atividades anuais, a "Semana da FESA". Messiant desenvolveu esta análise em um artigo publicado em uma revista francesa em março de 1999. Ansiosa para poder voltar a realizar trabalhos de campo em Angola, e sem ocultar suas posições, não deixando, contudo, a prudência de lado, publica, voluntariamente, seu trabalho na referida revista, supostamente pouquíssimo lida em Angola.

Pouquíssimo lida? De fato, cinco meses mais tarde, um semanal angolano de oposição, o Agora, publica, em 28 de Agosto, longos extratos, traduzidos sem a sua revisão e autorização, em um momento do ano que coincidia com o aniversário do Presidente e com a "Semana da FESA" (Agora 1999). Precisamente, dois dias depois (30 de Agosto), o Público, o maior jornal português, também publica extratos do mesmo artigo, incluindo-os na sua primeira página! Desta vez, o artigo de Christine Messiant é definitivamente "internacionalizado" como crítica direta à pessoa do Presidente. A resposta do regime foi típica e astuta: em um outro semanal igualmente conhecido por veicular opiniões críticas, a Folha 8 , sai um artigo, em 11 de Setembro de 1999, intitulado "Savimbi envenena inteligentemente a FESA". $O$ artigo, citando fontes dos serviços secretos angolanos, relata que Jonas Savimbi (o então chefe da Unita, principal movimento rebelde), teria ordenado ataques à FESA, com o objetivo de atingir a própria figura do Presidente ... (este episódio foi divulgado, sob indicação da própria C. Messiant, em um Editors' Postscript, no final da edição inglesa do artigo sobre a FESA (2001: 309). Assim sendo, a marxista-trotskista Christine Messiant encontrar-se-ia sob as ordens de Savimbi, que era apoiado pelos racistas sul-africanos ... Como consequência deste episódio, Messiant permaneceu durante quatro anos impedida de voltar a realizar trabalho de campo em Angola. De certa maneira, ela poderia ter se orgulhado disso; mas, na realidade, isto a magoou muitíssimo, já que ela desconhecia a duração deste ostracismo. Finalmente, ela pôde retornar a Angola em 2004 (pouco antes de ser acometida pela enfermidade que, enfim, a venceria), em ocasião do lançamento de um livro sobre o poeta e fundador do MPLA, Viriato da Cruz, no qual fora publicado um importante artigo de autoria da própria Messiant (2004). 
Esta é a primeira vez que o artigo ora apresentado é publicado, na íntegra, em uma tradução correta ao português. Antes disso, em Junho de 2009, empreendi uma tentativa, contudo, fracassada, de publicá-lo em uma revista angolana de Sociologia. Obviamente, já se passaram quinze anos da redação deste artigo, de modo que sempre se poderá alegar que os fatos analisados por Messiant já não podem ser considerados atuais. Com efeito, devemos chamar a atenção dos leitores sobre o fato de este artigo ter sido redigido em 1998, no auge da guerra civil angolana. Mas, o quadro teórico construído pela sociologa francesa foi, de fato, ultrapassado em Angola? Ao contrário, há quem pense que ele foi mais do que confirmado, onze anos após a vitória militar do MPLA sobre a rebelião da Unita (2002). De qualquer maneira, a bibliografia sobre o neopatrimonialismo na África e no mundo deverá, obrigatoriamente, incluir o estudo pioneiro realizado por Christine Messiant. Por este motivo, oferecemos esta publicação, pela primeira vez na íntegra, em português.

\section{Michel Cahen}

\section{Referências}

Agora, 1999, “A Fundacão Eduardo dos Santos (FESA): A propósito da 'investida' do poder angolano sobre a sociedade civil", Agora, 28 de Agosto.

Messiant, C. 1999, “La Fondation Eduardo dos Santos (FESA): à propos de

l'investissement' de la société civile par le pouvoir angolais", Politique africaine, 73: 82-102.

Messiant, C. 2001, “The Eduardo dos Santos Foundation. Or, How Angola's regime is taking over civil society", African Affairs, 100 (2): 287-309.

Messiant, C. 2004, "Viriato da Cruz em Pequim: as provações de um revolucionário angolano. Esboço de um percurso e tentativa de interpretação. Ensaio", in M.

Laban ed., Viriato da Cruz. Cartas de Pequim, Luanda, Chã de Caxinde: 215-360.

Messiant, C. 2008-2009, L'Angola postcolonial. Vol. 1. Guerre et paix dans

démocratisation. Vol. 2. Sociologie politique d'une oléocratie, prefácio de G. Balandier, introdução de B. Lachartre, posfácio de M. Cahen, Paris, Karthala.

Messiant, C. 2006, 1961. L'Angola colonial, histoire et société. Les prémisses du mouvement nationaliste, Bâles, P. Schlettwein Publishing.

Apesar da assinatura de um novo acordo em Novembro de 1994 com a UNITA (União Nacional para a Independência Total de Angola), a paz estava ainda longe de ser alcançada quando, em 1996, aparecia um novo actor da vida angolana, com a criação da Fundação Eduardo dos Santos (FESA).

2 Criada ante mortem por e à volta do seu "patrono", o Presidente angolano, esta fundação diz inspirar-se em instituições semelhantes que existem nos grandes países democráticos e pretende, como estas, alcançar objectivos de progresso social, cultural e científico. As suas bases legais ainda não estão definidas, a proveniência dos seus fundos e a título de que nela intervém o Presidente da República permanecem bastante vagos, mas tudo isso, e até mesmo a própria Fundação, aparecem geralmente demasiado subalternos - pelo menos para certos membros do partido no poder, o MPLA (Movimento Popular de Libertação de Angola), que receiam (como dão a entender) tratar-se de uma tentativa do Futungo (o palácio presidencial) de marginalização do "partido". Entre o momento da elaboração dos estatutos e o da sua homologação pelo 
Conselho de Ministros, desenrolou-se em Luanda uma série de acontecimentos bem mais importantes: um aumento considerável do descontentamento social, uma ostentação das forças da ordem e, finalmente, a destituição espectacular pelo Presidente do seu Primeiro Ministro. As primeiras referências à criação da FESA são, nestas condições, bastante imperceptíveis.

Um ano mais tarde (alguns meses depois da formação do "Governo de Unidade e Reconciliação Nacional", o GURN, que conta com alguns ministros da UNITA, cujos deputados também entraram para o Parlamento num momento em que se elevavam rumores de guerra), a Fundação toma mais forma e visibilidade por ocasião da semana do aniversário do Presidente ( 28 de Agosto), marcada pela realização de um grande colóquio internacional, jogos e divertimentos populares, e pelo apoio da Fundação à candidatura do seu "patrono" ao Prémio Nobel da Paz. A FESA aparece então, um pouco mais claramente, como uma instituição na qual o Presidente da República intervém como pessoa privada e cujos fundos não são deste, mas sim de grandes sociedades internacionais e nacionais.

Em Agosto de 1998, finalmente (caminhava-se então sem equívoco - e dos dois lados para a guerra, como também para a realização de um congresso do MPLA), a "semana da FESA" é nitidamente mais ampla: a Fundação apresenta as suas primeiras realizações; os seus doadores aparecem mais publicamente, como também as suas ramificações angolanas, os seus sectores de intervenção e a sua dimensão internacional. E, desta vez, ela está rodeada por um "culto de personalidade" tal que uma parte da imprensa independente ultrapassa a "linha vermelha" que se fixara e, respeitando as devidas formas, denuncia o escândalo ${ }^{1}$, sublinhando o contraste chocante entre a negligência da acção de um governo que o Presidente nomeia e preside e estas iniciativas parciais e ostentatórias em seu próprio nome - entre "tanta festa" e "tanta miséria" em meio a rumores de guerra.

5 Além deste sentimento de escândalo (largamente compartilhado pela população luandense, sem que no entanto isso impeça de modo algum que numerosas e eminentes personalidades públicas e privadas, instituições angolanas, grandes sociedades estrangeiras ou representantes da comunidade internacional acreditada participem nesse evento), o que se passa com a FESA? Vamos sobretudo aqui observá-la no que ela mostra, na evolução da "economia política real" de Angola, das relações entre o público e o privado e dos modos e efeitos da privatização do Estado. Com efeito, a FESA constitui ao mesmo tempo um elemento menor desta evolução global sob certos aspectos, mas também o último "fruto" de um conjunto de situações que, de certa forma, mostra a que ponto chegaram esta privatização e, de uma maneira mais geral, as relações do poder angolano com as instituições e a sociedade. E tentar-se-á indicar de forma breve as suas novas dinâmicas numa situação de "nem guerra, nem paz", em que o conflito político-militar com a Unita não está resolvido.

6 A privatização do Estado em Angola foi feita por apropriações privativas, ilegalidades, desinstitucionalizações que se verificam noutros sítios, mas que aqui tomam contornos bastante particulares, fundamentalmente devido ao facto da Angola independente ter sido até hoje um país em guerra ou numa lógica de guerra e cujo principal recurso, ou mesmo quase o único recurso, é o petróleo. Estas duas particularidades, cujos efeitos económicos, políticos e sociais são inextricáveis, implicam ambas, também, uma relação particularmente forte com o estrangeiro - quer se trate de parceiros estrangeiros da economia do petróleo e da guerra, quer da comunidade internacional stricto sensu 
associada, desde 1990, ao "processo de paz" angolano. Ambas também conferiram uma "natureza" especial ao poder e seu exercício, nomeadamente uma relação com as instituições em que o domínio da cúpula e dos aparelhos do Estado é central e permanecerá possível sob as diversas formas institucionais atravessadas.

7 Contrariamente a outros casos - e às numerosas análises da privatização do Estado como sendo uma nova impotência, uma despossessão tanto por "cima" (a nível internacional, sobretudo das instituições financeiras) como por "baixo" (a "sociedade civil") - Angola mostra um novo poderio não do Estado, mas do poder que o "detém", poder esse cada vez mais ligado a interesses internacionais (perante os quais as suas capacidades de negociação são grandes), cada vez mais centralizado e que, embora funcione e seja exercido fora ou ao lado da sua legalidade institucional, vai reforçando o seu controlo sobre as instituições e, ao mesmo tempo, sobre a economia legal e ilegal, ganhando assim uma certa promoção e "implantação"sociais.

\section{A longa "privatização" do Estado angolano e as novas bases da dominação}

8 Não se vai retomar aqui as profundas mudanças que conheceram a economia política real e o poder angolano desde a independência (Messiant 1994b). Apenas serão esquematizadas as suas principais etapas: sob o "marxismo-leninismo" oficial, e na base da apropriação de uma parte importante das receitas do petróleo pela cúpula do poder, a privatização de facto do "bem público", em proveito da nomenklatura do partidoEstado, conduz, desde meados dos anos 1980, a uma viragem clientelista; esta está ligada à possibilidade que a nomenklatura tem de rentabilizar, com um lucro considerável, os seus privilégios legais numa economia "informal", na prática "dolarizada", ilegal e da qual ela é a principal beneficiária. Sob a ameaça da guerra da Unita e dos seus apoios internacionais de então, o partido-Estado é obrigado, em 1990-1991, a proceder à liberalização económica e depois política, a negociar e a engajar-se numa "transição democrática" e até mesmo na realização de eleições que supostamente poderiam resolver o conflito armado. Graças à bipolarização estrutural do "processo de paz" e à atitude da comunidade internacional, e também ao facto de permanecer sozinho à testa do Estado e no controlo de todos os seus aparelhos e recursos, o governo poderá, durante esta transição, ao mesmo tempo reforçar a predação do petróleo (questão central na sua dominação) e alargar provisoriamente a redistribuição clientelista (Messiant 1994a, 1995a), começando a reconfigurar, através de privatizações legais, a sua apropriação do bem público. Com a imagem de defensor da paz que conseguiu apresentar face ao militarismo ostensivo da Unita, esta lógica, acompanhada por uma lógica política do mesmo tipo - cooptação e/ou neutralização das forças independentes - permite-lhe criar de novo uma coesão face ao "inimigo", voltar a ter crédito junto da sua base social (crédito esse que atingira o seu mais baixo nível em 1990) e ganhar as eleições de Setembro de 1992. No entanto, a guerra surgiu como uma consequência lógica - após eleições realizadas para consagrar (como fá-lo-ia uma guerra) um "vencedor absoluto" - de vontades hegemónicas das duas "partes", que não saem apenas intactas da "transição", mas também reforçadas: Savimbi recusa a sua derrota e, consequentemente, o "governo" não quer, como lhe pede agora a comunidade internacional, ver diminuído o seu poder, precisamente quando acaba de ser legitimado como jamais o fora e após ter podido confirmar quer a centralidade de 
um controlo sem partilha do Estado, quer as possibilidades de "acomodar" a liberalização económica e o multipartidarismo (que tanto temera) aos seus objectivos e modo de funcionamento. A terrível guerra de dois anos que se segue às eleições ${ }^{2}$, inaugurada por uma "batalha das cidades" que causou massacres cometidos por forças policiais e milícias não só de militantes da Unita, mas também dos seus "eleitores" visados por razões políticas e de identidade, permitiu um refor- ço do controlo do poder sobre o Estado e a sociedade. Já não tendo os recursos do partido único, o regime vai utilizar os da sua nova legitimidade democrática e da guerra: a implementação - no prolongamento da "batalha das cidades" e de uma sangrenta "caça aos Zairenses" (Mabeko-Tali 1995) - de uma ordem que, para além das vítimas que ocasiona, fomenta o medo no seio dos seus potenciais contestadores e garante a impunidade; uma partidarização ainda mais forte de todos os aparelhos do Estado, favorecida pela maioria absoluta do MPLA no Parlamento e pela sua dominação do governo; a sua posição internacional - a comunidade internacional apoia-o como governo legítimo (uma legitimidade ainda mais irrecusável depois do voto pela ONU, em 1997, de novas sanções contra a Unita) - e não se imiscui na sua maneira de governar mais do que o faz no exercício do poder pela Unita nas zonas que ela controla; e os países parceiros de Angola compreenderam (tal como os angolanos) que o MPLA detinha o poder com firmeza, e que era preciso lidar com ele para poder desenvolver os próprios interesses demasiado importantes e objecto de concorrência entre eles.

9 As condições de guerra (por imporem a força do poder e a evidência desta suscitar aproximações) vão permitir um aprofundamento das características já antigas ou recentes do "Estado" angolano, mesmo depois da assinatura dos Acordos de Lusaca, numa situação que não é de paz, mas sim um intermédio "anormal", provisório mas durável, entre a guerra e uma paz eventual, ou entre uma guerra e outra.

o poder, confiando na legalidade da sua maioria absoluta, poderá assim, de facto, mesmo depois da formação do GURN, continuar a agir "como no passado": fazendo ou desfazendo a lei, consoante as suas necessidades, de forma mais frequente, ignorando-a tanto no que concerne o respeito pelos direitos dos cidadãos e da oposição como o seu próprio funcionamento que se passa, em grande parte, fora da lei e das instituições e procedimentos legais. Visto a opacidade ser a regra para todas as contas cruciais (do petróleo, do diamante, do Banco Nacional de Angola e do Tesouro), o Parlamento vota anualmente, sem hesitação, um orçamento em que não constam somas consideráveis recebidas pelo "Estado" angolano; documento sem qualquer relação com a realidade, este orçamento, regra geral, não é executado. As decisões tomadas pelo governo ou pelo Parlamento podem ou não ter efeitos ou ser objecto de decretos de aplicação, isto é, quando não forem simplesmente modificadas ou sabotadas por outras decisões tomadas em instâncias que não são as que legalmente se devem encarregar disso: sob uma fachada democrática e institucional desejável, as interferências "do poder", longe de diminuírem, banalizam-se em consequência das negociações, das relações de força entre diferentes grupos, que determinam as políticas seguidas e que, reflectindo o aumento do poder da presidência, contribuem também para o seu reforço.

11 A centralização do poder para conduzir a guerra depois de 1992 vai permitir uma concentração crescente da riqueza ao nível da cúpula: a predação contínua do petróleo, as comissões sobre os grandes negócios de armas que continuaram, depois de Lusaca, para uma possível guerra em Angola e, a partir de 1996, guerras além-fronteiras, as comissões sobre as importações que dão aos que mais se beneficiam da predação e da 
corrupção um poder incomparável no sector privado, onde também podem passar a investir nas empresas legais; hoje eles dominam de facto, para além do sector económico público ainda vasto, todos os negócios "sensíveis", estrategicamente importantes - grandes empresas de segurança, de aviação, sectores de empresas públicas em leasing, companhias ligadas ao exército, à polícia - e conseguiram estender o seu poder ao sector vital da importação, sendo todas estas actividades extremamente rentáveis, mesmo exercidas legalmente. Esta concentração é grandemente favorecida pela política e pela concorrência de grandes grupos estrangeiros, com os quais os dirigentes angolanos têm interesse, do ponto de vista económico, mas também políticoestratégico, em consolidar alianças, grupos esses que procuram parceiros cujos estatutos possam garantir a segurança dos seus investimentos. A hegemonia económica legal do poder vai construir-se daí para a frente, de uma maneira geral, com a colaboração activa (bancos) e em associação com tais grupos estrangeiros, que contribuem assim para o reforço da base material do poder e, no seu seio, dos sectores mais poderosos: a presidência (e as hierarquias policiais), o estado-maior e, numa escala inferior, a hierarquia do partido.

A política económica geral, durante muito tempo ditada também por considerações estratégicas, permite, ademais, o desenvolvimento privilegiado das suas empresas, quer pelas suas coerências, quer pelas suas incoerências (leis, decretos, regulamentos votados, textos não assinados, créditos não desbloqueados, recurso a desvalorizações, diversas taxas de câmbio, atribuições e vendas em leilão de divisas, regulamentos para o desalfandegamento de mercadorias e taxas, autorizações de importação, acesso ao crédito bancário, etc.). A privatização legal não anula de modo nenhum o recurso à ilegalidade, mas articula-se com este. A inexistência ou a não aplicação de leis, a ineficácia da polícia económica e de uma justiça que não é obrigada a conhecer as leis permitem também delitos económicos maiores: tendo em conta os lucros possíveis e a impunidade, os grandes tráficos, nomeadamente de divisas e diamantes, continuam a ser feitos; as maiores dilapidações de fundos públicos e da ajuda internacional, os desvios nos bancos e nas empresas públicas, bem como os desvios importantes de mercadorias no porto ou no aeroporto destes últimos anos, implicando, no mínimo, a existência de cumplicidades ao mais alto nível do poder civil, policial ou militar, ficaram por ser "elucidados".

\section{As novas formas da distribuição clientelista}

Esta apropriação e extorsão, importantes em proveito da cúpula do poder, são no entanto acompanhadas por uma certa dispersão da riqueza: a dominação não se apoia apenas na ordem de segurança e no medo, mas também numa nova forma de redistribuição e no "fundo" sobre o qual esta é exercida: a miséria "legal", que resulta da total insignificância dos salários, de um desinvestimento ainda crescente dos serviços sociais públicos e de uma dependência generalizada da população em relação a um "mercado" formal e informal selvagem, cujo desenvolvimento levou à generalização da corrupção e da insegurança econômica, como também a um aumento considerável da violência social, policial e criminal.

14 Esta miséria, aliada à ausência de justiça e de direitos, confere uma maior eficácia ao sistema de cooptação-redistribuição/exclusão-marginalização iniciado durante a "transição" e agora aperfeiçoado, levando à implementação de um verdadeiro sistema 
de comprometimento generalizado. Aparentemente, este sistema destina-se legalmente, em primeiro lugar, ao que se pode chamar de nova nomenklatura do regime - deputados, ministros e vice-ministros, chefes do exército e da polícia, altos magistrados, mas também próximos do presidente, Conselho da República ${ }^{3}$, a quem se atribui, pelo exercício das suas funções, vantagens exorbitantes ${ }^{4}$, mas também a toda uma parte "da sociedade civil", nomeadamente um pequeno número de organizações não governamentais que se beneficia de subvenções do Estado. Este sistema tem um objectivo político: a "neutralização" dos opositores e dos independentes, que constituiu a política de fundo do poder angolano; associada à repressão e à intimidação, ela vai de facto permitir a sua domesticação ou marginalização - só a entrada, em Abril de 1997, dos deputados da Unita no Parlamento tornou possível uma expressão audível da oposição, rapidamente travada para, em 1998, ser finalmente abafada. Mas, na realidade, o sistema beneficia ultra-maioritariamente os seus próprios homens e constitui uma forma de redistribuição.

Este sistema aplica-se também cada vez mais, sem publicidade, a indivíduos que o poder quer atrair, tenham já eles ou não acesso a privilégios pelo exercício das suas funções, sejam ou não servidores do Estado ou dirigentes de organizações económicas ou civis; privilégios que podem não ser renovados, prebendas recuperáveis e (...); estes "presentes", que oferecem possibilidades incomparáveis às de um cargo mesmo bem pago em dólares e que têm para alguns, para além de um interesse "em si", o de tirar proveitos "colaterais", legais ou informais e mesmo ilegais, assegurando assim o poder, de maneira geral, aos seus servidores e protegidos, a impunidade que ele acorda a si mesmo. Este sistema "compromete" na verdade centenas de responsáveis do Estado e da administração, empresas, "patrões” diversos (responsáveis de federações desportivas, de organizações sindicais ou profissionais), jornalistas, quadros superiores, sejam eles já pessoas de confiança ou outras que se queira neutralizar, tecendo uma teia de interesses e de dependências que não impedem autonomismos e rivalidades, mas que os tornam mobilizáveis em caso de necessidade (no apoio ao poder contra a Unita ou nas reivindicações sociais ou democráticas da população, como também nas lutas de facções).

16 A dispersão da riqueza resulta, na maior parte, do desenvolvimento do sistema clientelista. Recente no seu maneio ao nível da cúpula, é-o também na sua utilização a todos os níveis. Com a liberalização, muito poucos dos que dele beneficiam, contentamse em redistribuí-lo ou revendê-lo "simplesmente" no mercado informal. Investem, tal como a cúpula do poder, nos sectores e a níveis por esta deixados: no imobiliário e agora já não só no estrangeiro, mas também em Luanda, capital protegida que conhece a sua primeira explosão desde a independência; de uma maneira muito geral, também na "empresa" - isto é, em grande parte, o comércio e serviços e sobretudo a importação que cobre quase sozinha a apelação de "import-export".

Daí a existência actualmente de uma sobreposição generalizada do público e do privado que recorre também (tendo em conta o custo e a incerteza da vida num país "que ainda não está em paz") à utilização muitas vezes combinada do legal e do ilegal, a montante (desvios, tráficos, jogo com o câmbio) ou a jusante: mercadorias desviadas antes de serem registadas no porto ou no aeroporto ou antes da chegada aos armazéns e que são directamente colocadas nos mercados informais ou em empresas legais que não são as que estão acreditadas para recebê-las. Acontece que uma parte dessas mercadorias não é vendida legalmente, mas sim confiada ao sector informal, mais rentável. Com a 
utilização dos favores que lhe confere por vezes a lei no quadro das suas funções, relações e proteç̧ões, esta nova nomenklatura encontra-se em posição muito privilegiada face aos seus concorrentes independentes, o que faz, cada vez mais, mais beneficiados no seu seio: deputados, generais e coronéis, administradores, conjuntamente com outros antigos ou novos "empresários do MPLA" (entre os quais, os que pertecem à "nomenklatura" não pública que beneficia do mesmo tipo de liberdades), altos quadros e profissões liberais, dirigentes de organizações económicas, sindicatos, ordens profissionais "amigas", etc., que ocuparam largamente o terreno que dantes pertencia aos candongueiros (traficantes), investiram nos novos negócios muito rentáveis dos táxis colectivos e transportes, restaurantes, hotéis e pensões, supermercados, clínicas e farmácias e estabelecimentos de ensino privado. Os mais bem-sucedidos podem, por sua vez, lançar amigos e parentes que se tornaram gerentes ou que podem mesmo, a uma menor escala, instalar-se por conta própria.

Por conseguinte, ao longo destas cadeias de redistribuição, há um efeito de controlo social e de submissão política poderoso, uma real implantação "do poder"; este não é um "monstro frio" face ao que seria "a sociedade", tanto mais que os seus beneficiários, mesmo muito minoritários, representam cada vez mais uma força económica e social e que, na miséria generalizada, deles dependem muitas pessoas - empregados, domésticos, famílias, clientelas à procura de segurança e de "bons patrões". Para além disto, este controlo social não é apenas o resultado de uma estratégia deliberada do poder, real e implementada desde a transição, mas também da sua capacidade, num contexto de reforço do partido-Estado em situação de guerra, de utilizar evoluções individuais, entre as quais as reconversões económicas de antigos quadros públicos no novo contexto liberalizado - muitas vezes elas mesmas enxertadas também no internacional e nas divisas que este traz, como nos "parafernais" do "Estado de direito" - e de cooptar politicamente alguns dos que, muitas vezes por acumulação de riqueza inicialmente ilegal, conseguiram seguir um caminho mais individual rumo ao sucesso económico e social. É certo que a generalização da corrupção a todos os níveis não deixa de "produzir" independentes, mas estes não constituem, nestas condições, ameça económica ou política notável.

\section{A FESA no dispositivo clientelista}

19 A Fundação Eduardo dos Santos pode ser analisada, a um primeiro nível, como sendo um produto e o remate do sistema geral de dominação clientelista e o indício do reforço do poder presidencial. Na verdade, o que é a FESA?

Na base, simplesmente, esta fundação, como outras, detém dinheiro privado que não é seu, para o evergetismo pessoal do seu "fundador e patrono", que nela intervém como pessoa privada, mas que é, também, como não deixa de lembrar a Fundação ${ }^{6}$, o Presidente da República de Angola e do MPLA, o partido da maioria no poder.

21 Para o efeito, a FESA - aliás jogando, como o faz o Estado angolano na gestão muito estratégica do seu petróleo, com as rivalidades entre os interesses económicos estrangeiros e os "seus" Estados - "taxa" (direitos de entrada, contribuições para diversos projectos) as grandes companhias estrangeiras interessadas no "negócio" angolano (sociedades petrolíferas e para-petrolíferas, outras implicadas no diamante e nos grandes projectos de infraestrutu- ras, na construção e em certos bancos), como as grandes empresas angolanas (Sonangol para o petróleo, Endiama para o diamante que 
sempre dependeram directamente não das decisões do governo, mas das do Presidente), como também diversas empresas mais pequenas que querem figurar neste "bloco" duplamente interessante por estar próximo do poder e trazer benefícios. Até então, estas grandes sociedades estavam (e cada vez mais com o abandono dos serviços públicos pelo Estado) implicadas em obras colaterais às suas actividades (estradas, água, electricidade, infraestruturas diversas, escolas, centros de saúde), mas em seu próprio nome.

O Presidente angolano "repatria" assim para a sua própria pessoa uma parte deste benefício e redistribui-lo, todos os anos, de maneira "agrupada", durante a "Semana da FESA" - "forma instituída pela Fundação para a celebração do aniversário do seu Patrono" (sou eu que denoto, mas o objectivo destas obras está explícito) - que dá lugar forçosamente a publicidades, votos de felicidades e agradecimentos. Numa total deserção pública e miséria (engendradas pelo custo da "defesa da soberania" e da extorsão considerável e impune do bem público pela cúpula do poder, seus fiéis e agentes) em domínios que o Estado abandonou completamente e que muitos dos seus reponsáveis também vandalizaram, o chefe do Estado subtrai de facto o que, provindo dos seus parceiros estrangeiros ou de grandes sociedades nacionais, poderia, sob outras leis e outros costumes, alimentar o orçamento do Estado, aparecendo, graças a este dinheiro, como um benfeitor.

De uma maneira geral, o que evidencia o programa da Fundação é, na realidade, a preocupação pelo povo, o Estado de direito e o futuro. Para além do progresso científico e técnico, caro ao "engenheiro José Eduardo dos Santos" e que justifica a organização todos os anos, sob a égide da FESA, de grandes “jornadas técnico-científicas” reunindo muitos especialistas internacionais, as acções da Fundação concernem grupos e temas ligados tanto à trágica situação angolana como à ciência e à modernidade internacionais - como, por exemplo, desordenadamente, a formação dos quadros, a moral cívica, a Internet, as mulheres, as crianças, os jovens, os deficientes e velhos, a desminagem, a sida, a ecologia sob todas as formas (da protecção dos oceanos aos espaços verdes), etc. - e englobam, na verdade, praticamente todos os "grupos vulneráveis, "grupos-alvos" e temas "internacionalmente homologados".

24 A empresa Fesa mostra também, um pouco melhor, após dois anos, não só a confusão das fronteiras entre os estatutos presidencial e privado do seu "patrono" (confusão que vem desde a origem e fundação, entre o público e o privado), mas também as formas complicadas de encabrestamento que ali se tecem. Em certos domínios, a FESA não redistribui, vindo sem equívoco fazer concorrência ao Estado e prosperar sobre a decadência deste. Citando apenas um exemplo: quando a UAN (Universidade Agostinho Neto) foi deixada sem meios, com a excepção dos sectores financiados pelo extrangeiro e que, para viverem decentemente, os seus professores tiveram que trabalhar (para obterem dólares) como consultores no sector privado, o "grande desafio" da FESA foi, na verdade, em associação com a Sonangol, a criação de uma "Universidade Nova", onde o ensino de qualidade internacional, desejado pelo Presidente, seria assegurado por angolanos diplomados escolhidos ou preparados para o efeito por professores estrangeiros, e que concentraria as disciplinas técnico-científicas mais susceptíveis de atrair a cooperação estrangeira, pública e privada.

Além disso, a FESA não funciona unicamente com fundos privados: entre as realizações inauguradas ostentosamente em Agosto, algumas não foram só financiadas (e às vezes de forma alguma) pelo dinheiro das companhias privadas de membros da FESA ou por 
ela mobilizadas, mas pelo do próprio Estado; pode-se assim saber que tal centro para crianças abandonadas do Cacuaco, inaugurado em Agosto de 1998, foi financiado pelo governo angolano e que alguns ministérios ou ainda o governo provincial de Luanda também contribuíram para o financiamento de diversos projectos. Na verdade, a FESA colabora com frequência com o "Estado", ministérios ou administrações locais, intervindo como "complemento da acção do governo" ou em associação com ele, sem que se conheça no entanto, salvo excepção, as contribuições respectivas, ou exclusivas, do Estado e da Fundação nas diversas realizações oferecidas aos angolanos na última semana de Agosto, pelo Presidente. 0 certo é que o lançamento da terceira campanha de vacinação contra a poliomielite se insere também na "Semana da FESA".

Mas este dinheiro, venha de onde vier, volta muitas vezes para o "sector público" por intermédio da Fundação; a FESA pode assim apresentar, ou pelo menos inaugurar, numerosas realizações: escolas e centros de saúde, equipamentos municipais (estádios, mercados, jardins) reabilitados ou inteiramente novos. O Presidente da República relança, assim, financeiramente o Estado; "ajuda" os Ministérios da Educação, da Reinserção Social e da Saúde, oferece à polícia nacional meios de transporte ... Aliás, a FESA inclui nas suas instâncias de direcção membros do governo; por conseguinte, não é estranho, tendo em conta estes cruzamentos de fundos e de pessoas, que se tenha ouvido na rádio, em Agosto de 1998, um elogio de reconhecimento pela acção da Fundação e do seu patrono feito pela vice-ministra da Saúde (membro da FESA), e que a reitora da Universidade (que não é membro da FESA, e pertencendo a um sector de que se dirá ser menos dotado) tenha reunido de urgência os professores efec- tivos (na altura em greve) para discutir sobre a oportunidade ou não da UAN acordar também um doutoramento honoris causa a José Eduardo dos Santos.

Porém, a semana do seu aniversário é também para o Presidente angolano - que vive afastado de Luanda no Futungo, de onde só sai acompanhado por um dispositivo policial impressionante e que não voltou a visitar as províncias desde 1992 (na altura por causa das eleições) - a ocasião de encontrar directamente o povo e de mostrar a sua benevolência para com ele. Nas instituições do Estado (hospitais, prisões) que então visita (instituições essas que na maior parte dos casos estão em condições catastróficas), oferece numerosos donativos - roupas e alimentos, material escolar, brinquedos, televisões, etc. - directamente a angolanos pertencentes a diversos grupos, especialmente desfavorecidos: crianças, amputados, deslocados, etc. Têm também lugar manifestações desportivas e festas populares, dado que a FESA quer contemplar particularmente a juventude, o futuro do país, a quem a "semana" oferece uma série de lazeres de natureza "desportiva, cultural e recreativa".

É certo que tudo isso não é muita coisa para compensar a devastação pública, apesar da acumulação de inaugurações, da qualidade da participação mundana nacional e internacional, bem como da cobertura intensiva dos média, que também se apropriam de belas quantias. Mas durante esta semana, o povo, ou pelo menos uma parte deste, sobretudo de Luanda, tem "pão [ou antes, cerveja] e brincadeiras", o que muda em relação ao quotidiano.

Para além da sua contribuição para as acções do governo e a sua intervenção directa a favor do povo, a FESA apoia também uma série de outras organizações da sociedade civil. Algumas aparecem durante a Semana da FESA, como em 1998 o Fundo, que se ocupa da desminagem e de que é presidente a "Primeira Dama" (e na FESA, membro do Conselho Geral). Mas a FESA apoia também a Associação de Apoio às Mulheres Rurais de 
que é igualmente presidente a "Primeira Dama"; ela cofinancia, com diversos ministérios, tal organização ecológica e patrocina, sempre em associação com vários ministérios, tal fundação para a protecção da natureza; financia ou cofinancia também, ou apoia ocasionalmente, um certo número de associações nacionais, locais e de ordens profissionais (engenheiros, advogados, arquitectos, etc.). Toda esta rede "civil" que gravita permanentemente em torno da FESA interessa-se pelo que se pode chamar de "canais" de captação dos fundos internacionais; esta rede faz trabalhar empresas amigas; dá vantagens aos dirigentes destas associações e aos que a elas estão ligados ou que delas recebem de vez em quando encomendas e benefícios, vantagens que, mesmo sendo legais, garantem uma situação económica, relações e uma base social bastante apreciáveis; captanto de forma quase automática os fundos das grandes sociedades nacionais, tem tendência, no contexto da estrutura do poder angolano e perante a notoriedade (ou mesmo simplesmente as facilidades de intervenção) que este alto patrocínio confere, a captar não só os fundos internacionais privados que a alimentam estruturalmente, mas, também, ao credibilizar e reforçar as organizações da rede, a atrair outros, em detrimento de associações da sociedade civil que, na economia política angolana, são marginalizadas.

31 Uma análise mais apurada se impõe. Embora, infelizmente, só se conheça de forma muito parcial as contribuições dos diversos doadores, sabe-se no entanto que os órgãos de direcção da FESA (e das outras fundações e associados desta rede) integram personalidades, tanto do sector público como do privado, “incontestáveis" e até mesmo com prestígio (tal como Mandela para a Fundação Kissama), que lá estão sobretudo para caucionar; outros usufruem os numerosos benefícios pessoais ligados a estas empresas sem fins lucrativos, outros participam nas tomadas de decisão, outros ainda são cooptados para esses órgãos com o fim de serem neutralizados. Os “alvos" de intervenção da FESA mereceriam igualmente um estudo detalhado: no que concerne as suas escolhas de quem ela ajuda, com quem colabora, ou ainda de punções sobre certos ministérios ou sectores governamentais; no que aí diz sobretudo respeito à construção da imagem pessoal não sectária do Presidente, mas que é marginal no seu sistema clientelista global (por exemplo, reconstrução de uma igreja adventista na província, ou ainda doação de "vestuário e alimentos" a chefes tradicionais, na realidade, muitas das vezes reduzidos à miséria após a sua breve hora de glória com vista às eleições) e no que concerne ao que, sob uma certa dispersão, aparece bem como uma nítida concentração na capital e em certos bairros desta (Sambizanga, o seu bairro natal, Cazenga ...) e que o Presidente "cuida" em especial.

Queria apenas, aqui, ilustrar rapidamente o que a FESA revela sobre a "privatização do Estado", a descentragem do poder angolano em relação a este Estado e a sua contribuição para a ruína deste. Através da Fundação, o clientelismo do Presidente angolano utiliza recursos de que o "poder" angolano dispõe "colectivamente"; ele toma formas reveladoras dos novos modos de dominação, em especial no que concerne às articulações público-privado, à relação com o internacional e o "Estado de direito", ao tipo de controlo social e de legitimação da sociedade - e, mais precisamente, a sua investida à dita sociedade civil - e reforça os meios de dominação deste poder colectivo. Mas a pessoa que "patrocina" esta fundação é evidentemente excepcional e a FESA, que nasceu com o reforço do poder presidencial, contribui por sua vez para o reforço deste: com ela, "o engenheiro José Eduardo dos Santos" encabeça de certa forma a sociedade civil e fá-lo, sintomaticamente, na posição de "patrono", utilizando os trunfos 
incomparáveis de um presidente da República que é chefe do governo, chefe do partido e das forças armadas, que controla estritamente as polícias, recebe o dinheiro do petróleo não orçamentado, aferrolha a sua atribuição e se beneficia, em primeiro lugar, da concorrência entre sociedades e Estados estrangeiros pelos recursos e mercado angolano.

\section{A estratégia presidencial na estratégia do poder}

33 A FESA vem assim, de certa forma, "simplesmente" coroar o dispositivo clientelista geral. Ela insere-se também num clientelismo pessoal do Presidente que a ultrapassa, que é, como já aqui foi referido, ao mesmo tempo público e discreto e é exercido nas instituições públicas e na "sociedade civil", económica e não económica: a presidência é a principal distribuidora dos favores não "institucionais" e, devido à dinâmica da situação, é a ela que as pessoas, cada vez mais, se dirigem para obtê-los. Porém, este clientelismo pessoal inscreve-se também numa verdadeira estratégia presidencial, que se desenvolve (e deve ser analisada) em função dos diversos desafios, hierarquizados mas cruzados, estruturando a situação de "nem guerra, nem paz": o desafio, vital, do conflito com a Unita; o preocupante desafio do desenvolvimento da crise social; e finalmente o desafio das rivalidades internas ao poder.

Atendendo a que a miséria, conjuntamente com a impunidade, confere ao sistema de dominação clientelista uma eficácia social, a própria aceleração da lógica de predação conduz a uma agravação "excessiva" desta miséria: ela já não atinge apenas os que, não sendo "representados" na cúpula, foram há já muito tempo excluídos e marginalizados, ou os que, em baixo da escala, deixaram de receber as migalhas do sistema; ela atinge a grande massa da população, a base eleitoral do regime (cujas classes médias se pauperizam dramaticamente quando não têm acesso aos postos ou favores pagos em dólares) e até mesmo as forças da ordem, soldados e polícias, que não são nem melhor nem mais regularmente pagos que os outros agentes do Estado. Deste estado de coisas, resulta, "em baixo", uma generalização do roubo e dos desvios, da corrupção (a gasosa), da ilegalidade e da violência, agravadas pela impunidade acordada aos homens armados do regime, com a situação a piorar desde a assinatura dos acordos de Lusaca e a população entregue à ajuda das Igrejas, organizações internacionais e ONGs. Enquanto que a opulência da nova nomenklatura e dos seus aliados se torna cada vez mais visível, cresce no seio da população, sobretudo em Luanda (que concentra mais do quarto desta), um profundo ressentimento contra esta decadência e a sua atribuição à corrupção de um poder em que o Presidente é notoriamente cada vez mais poderoso (mesmo que, contrariamente a outros dirigentes, ele não apareça entre os grandes "empresários") (Mabeko-Tali 1997). Existe, pois, para o poder no seu conjunto, e para o Presidente em particular, um "problema social" que, apesar de ser contido pela não resolução do conflito com a Unita e pelos meios de segurança, cria um problema para o regime em relação a este conflito. Na verdade, ele não consegue resolvê-lo socialmente - toda a sua lógica opõe-se a uma satisfação "legal" das "necessidades do povo" - nem política nem democraticamente, na medida em que qualquer abertura neste domínio traria o risco de provocar uma expressão do descontentamento, ou até mesmo permitir a uma Unita política, em caso de normalização, de "capitalizá-lo".

A tudo isso, se acrescenta o agravamento das divisões e lutas no seio do próprio regime. A concentração da riqueza na cúpula do poder, em associação com interesses 
estrangeiros, provocou a marginalização de certos sectores, nomeadamente de um número bastante grande de empresários angolanos inicialmente favorecidos. Ela também se fez acompanhar por uma agudização das rivalidades a todos os níveis, incluindo na cúpula do regime, onde as lutas de influência, as divergências entre facções, antigas mas até então inconstantes, tendem a cristalizar-se à volta de verdadeiros grupos de interesses financeiros, sendo estes interesses, ao mesmo tempo, a sanção e o desafio das lutas de poder. 0 estado-maior do exército entrou assim, a partir da guerra de 1992, na grande corrupção como um actor relativamente independente, cujo poderio e interesses económicos vieram reforçar o seu peso nas tomadas de decisões; embora ele aja de maneira geral em "harmonia" com os intersses colectivos do poder, os generais constituem também, para a presidência, concorrentes económicos e uma ameça para o seu controlo das forças de coerção. Quanto ao partido, em Dezembro de 1991, saiu reforçado de uma luta pela vitória eleitoral em que os "argumentos" do poder foram a reunificação contra o inimigo histórico - a Unita - de toda a "família do MPLA" desunida ou desmobilizada e a promessa de que, uma vez os "erros" reconhecidos, voltar-se-ia ao "MPLA das origens" para o qual "o mais importante [era] resolver os problemas do povo". Despolitizado e tendo cooptado todas as "forças vivas" que podia (e continuando a "importar" para o seu seio divisões e contradições), o partido foi um instrumento crucial da relegitimação popular do poder e, em seguida, à volta das eleições, da remobilização do seu eleitorado para a guerra. Com o início da guerra, o MPLA decaiu rapidamente como partido de massa, mas a sua estrutura reforçou-se e a sua implantação política e económica no Estado e no sector privado permaneceu forte. Deixou de ter lugar estatutário na nomenklatura legal, dependendo do Presidente para ter acesso à predação do petróleo voltando, porém, a ser um lugar e um desafio de poder, enquanto que diversas facções suas, marginalizadas ou hostis à evolução do regime, podem, apesar das suas divisões, fazer frente contra o Presidente - como foi, aquando do último congresso, a eleição, contra o candidato do Presidente, de um dos raros dirigentes a terem manifestado (prudentemente) tendências reformistas e moderadas - e ser ouvidas por uma base eleitoral em estado de plena desafeição.

36 É neste quadro de uma deslegitimação perigosa e de contestações internas que se vai desenvolver a estratégia presidencial. Esta exprime, em parte, uma estartégia colectiva (que ela tende dominar cada vez mais), que tem como base a transformação das bases materiais de um poder agora enraizado nos interesses financeiros legais e ilegais, individuais e colectivos, ligados à situação de "nem guerra, nem paz" (e, em parte, ao rearmamento para uma possível guerra e, desde 1996, para as guerras levadas a cabo no exterior) e à impunidade especial que esta situação favorece. Mas ela procura também reforçar o poder presidencial face aos seus contestatários ou rivais e dissociar-se das responsabilidades do poder e dos alvos possíveis do ressentimento popular.

Trata-se, em primeiro lugar, de uma estratégia de legitimação que passa pela consolidação da imagem do Presidente como sendo um homem de paz, voltado também para o mundo e para a modernidade democrática, pouco ligado ao poder e sensível ao sofrimento do seu povo. Esta imagem personaliza aquela que o regime se quer dar colectivamente e é, antes de mais, evidentemente, uma construção face à Unita e ao seu chefe - o presidente angolano aparece exactamente como o inverso do belicista, "fundamentalista", bárbaro, sedento de poder e proximamente "criminoso de guerra" Savimbi. Mas tem também como "função interna" distinguí-lo, dentro do seu campo, dos que podem ser os "radicais" - militares do estado-maior e "linha dura" do partido 
-, a cujas pressões o presidente angolano poderá estar sempre submetido, mas às quais resistirá enquanto possível. Enquanto cresce na população o sentimento de que o poder não pode funcionar "em paz" e que o Presidente é o principal responsável pela deriva das negociatas, todas as oportunidades públicas e privadas, nacionais e internacionais de José Eduardo dos Santos são aproveitadas para a dispendiosa contrução desta imagem, na qual, evidentemente, se inscreve a FESA.

Quanto à modernidade democrática, também desejável para a legitimação internacional, mas que dificilmente pode ser advogada tendo em conta as práticas do regime, será antes consagrada pela multiplicação dos organismos supostos manifestar e consolidar o "Estado de direito", pela atribuição de títulos de Doutor Honoris Causa ao Presidente angolano, pelas mais diversas universidades brasileiras públicas e privadas e será, sobretudo, representada por jovens ou menos jovens diplomados e "tecnocratas" oriundos do partido, não (ou já não) pertencendo, porém, às suas instâncias dirigentes. Trata-se, aí também, para o poder angolano no seu conjunto de se situar convenientemente no concerto da democracia e da competência mundializadas. Mas trata-se também de uma estratégia presidencial, iniciada desde os anos 80 , tendo como objectivo, conjuntamente com o jogo sobre as facções divididas do partido, garantir uma base pessoal, inicialmente inexistente mas reforçada desde então, especialmente, com promoções no governo.

A partir de 1992, esta política de promoção de quadros escolhidos pelo Presidente vai ter como fim, em particular, o acesso destes à direcção do partido. Na verdade, depois das eleições, este último voltou a ser uma aposta pelo poder. Daí uma nova investida do MPLA pela presidência, "colectivamente" através de uma redistribuição, permitindo ao partido criar as suas empresas, mas também pela passagem das finanças do MPLA para as mãos de uma pessoa de confiança, pela associação ao poder de decisão real de somente certos membros das suas direcções nacionais, bem como pela concessão personalizada de favores presidenciais, alargada também a certos membros das direcções regionais e locais. Não é aqui o lugar indicado para analisar isso, mas esta política foi confirmada no Congresso de 1998 pela eliminação dos seus principais potenciais opositores - cujos raros dirigentes (particularmente o secretário-geral) manifestaram intenções democráticas e críticas a seu respeito - e pela subida ao comité central dos "seus" homens, tudo isso após uma campanha activa sobre o tema da "renovação" e da "juventude" e pelo jogo da "democracia interna". Apesar da surpresa e decepção da "comunidade internacional", esta operação é perfeitamente coerente com a estratégia de controlo e de marginalização levada a cabo ao mesmo tempo pelo poder e, muito além do partido, pela presidência, revelando também dinâmicas mais gerais de asfixia da democracia; ela garante ao Presidente um instrumento domesticado, enquanto o congresso decide também (consagração de novo da partidarização do poder depois de 1992) que a partir de então os governantes deveriam ser dirigentes do partido.

Esta estratégia do Presidente exprime-se também, de forma discreta, nas lutas de interesses e de influência, especialmente com os seus concorrentes económicos mais independentes, os generais, com os quais serão feitos acordos e aceites partilhas (diamante), mas não sem algumas crises; a presidência consegue às vezes negociar, outras destituir de funções que são simultaneamente económicas e políticas, nomeadamente com a nomeação de um ministro da Defesa não ligado ao estado-maior 
ou a passagem recente sob o seu controlo da empresa rentável e sensível de importações militares, ou ainda o aumento do poder da guarda presidencial.

41 As tomadas de controlo e as marginalizações, a construção de uma imagem de homem de paz são importantes face à Unita ou ao bloco no poder; porém elas não podem solucionar a "questão social", a perda da legitimidade do regime na sua base eleitoral; por terem sido as eleições adiadas sine die por causa da "não-paz", esta não será exprimida num escrutínio, mas manifesta-se, cada vez mais e cada vez mais amplamente, por um ressentimento contra o poder. Como prova da excepcional margem de manobra de que dispõe, o Presidente vai, especialmente depois dos acordos de paz - que poderiam fazer "cair" uma das "justificações" do descalabro social dissociar-se cada vez mais da política levada a cabo por um governo que ele mesmo nomeou e preside e cuja "ineficácia" e "inssucessos" são devidos em parte às suas interferências consideráveis. Ele dirige-lhe regularmente (mensagens do Nono Ano) críticas muito duras, despede periodicamente as suas equipas económicas - apontadas, com a ajuda de uma parte da imprensa privada, como responsáveis pela miséria popular - e, quando o descontentamento atinge um nível ameaçador, demite o seu Primeiro Ministro.

\section{Estratégias e dinâmicas de guerra}

Pode ser interessante, para ilustrar rapidamente as dinâmicas socio-políticas mais gerais da dominação clientelista e do reforço do poder presidencial, voltar a este episódio e ao que está em jogo e se prepara na primavera de 1996, ano da criação da FESA. Face a um descontentamento massivo, que toca até os militares e é concomitante com diversos apelos para manifestações e uma proliferação de panfletos denunciando a corrupção do poder, a resposta será, antes de mais nada, uma demonstração impressionante das forças da ordem (entre as quais a Polícia de Intervenção Especial) nas ruas da capital no dia $1^{\circ}$ de Maio e, em seguida, a prisão e a acusação de um protestador pacífico de "atentar contra a segurança do Estado". Virão em seguida (6 de Junho) o discurso estrondoso do Presidente à Nação, anunciando uma "nova vida" (Nova Vida) e a crítica radical que faz à política do governo, ao escândalo da miséria do povo e à corrupção exorbitante existente na cúpula do poder, despedindo não só os ministros da área económica, como se tornara costume, mas também o seu próprio Primeiro Ministro. Pela primeira vez desde 1992, numa altura em que as manifestações só podiam ter lugar quando autorizadas, o "povo" (grupos) - especialmente dos bairros de Sambizanga, Cazenga, etc - sai espontaneamente à rua em Luanda, com camisolas com a efígie do Presidente para o apoiar, mas também para escarnecer do Primeiro Ministro (escolhido após as eleições e a degeneração étnica da "batalha de Luanda" de 1992, especialmente por "pertencer" à etnia que mais votou pela Unita), gritando slogans contra os Ovimbundos; em seguida, é votada pelo Parlamento, quase subrepticiamente, uma lei que estabelece que os novos bilhetes de identidade deverão mencionar a "raça" do titular. Mais ainda, em Agosto, é lançada uma operação massiva de expulsão de "traficantes" estrangeiros (sobretudo africanos, libaneses e asiáticos), operação essa a que foi dado o nome sugestivo de "Câncer II".

Existe nesta sequência de factos elementos importantes e reveladores de estratégias que não são apenas as de "certos sectores do poder", mas sim do poder em geral, em que a presidência, reforçada, é dominante, ao mesmo tempo que prossegue uma 
política própria. Perante uma crise social que se agrava cada vez mais pelas marginalizações massivas provocadas pelo custo de manutenção do aparelho de segurança e o nível da predação e da corrupção, a "resposta" clientelista (de que faz parte a FESA), mesmo permitindo uma medida de controlo social, é muito insuficiente, para além do facto de alimentar um sentimento de humilhação. A política de dissociação das responsabilidades no desastre social levada a cabo pelo Presidente só pode enganar os nacionais ou estrangeiros que têm interesse nessa ilusão. Perante o aumento do descontentamento, perigoso para a sua legitimidade e, por conseguinte, para o seu poder em caso de se caminhar para a paz, o que seria inaceitável em caso de guerra, o regime poderá recorrer aos recursos que lhe oferecem uma situação de "nem paz, nem guerra" que, "face ao inimigo", comporta a expressão da crise social e da agudização das rivalidades e oferece meios repressivos e de segurança, ao mesmo tempo que tenta enquadrar novamente uma base social.

Incapaz de encontrar soluções sociais ou democráticas, esforça-se não só, como foi o caso em 1992, para capitalizar as tensões e exasperações sociais mas, também, uma vez que estas se foram agravando sem que uma solução tenha sido encontrada, para organizá-las e orientar, em direcção de outros, um ressentimento que pode, "independentemente da vontade do inimigo", ter como alvo o poder e especialmente o Presidente. É, na verdade, sob a direcção deste que, tendo em vista a defesa dos interesses comuns do poder e da nomenklatura, mas jogando também com as suas divisões e contradições internas, são designados, através de acções policiais, leis e média, vários alvos devidamente identificados (alvos esses exteriores ao poder na medida do possível, mas agora também internos devido ao perigo que podem constituir), que poderiam centralizar este ressentimento (traficantes estrangeiros, Ovimbundos, mestiços e brancos ...). E é a própria presidência que se engaja numa nova mobilização da população, cujo prelúdio é marcado pela formalização do apoio dos partidários do Presidente, em Junho de 1996, numa organização permanente, intitulada Movimento Nacional Espontâneo (sic), organização essa que vai tentar reunir uma parte da juventude proporcionando-lhe lazeres, viagens, excursões e que (...) dá também o tom "presidencial" (menos benigno que o da FESA) da mobilização do povo e da sua dinâmica miliciana.

Assim, o ressentimento contra o poder e as suas próprias rivalidades internas vão associar-se às tendências pesadas de um regime que repousa sobre ilegalidades e impunidade autorizadas, ou até mesmo condicionadas pela anomalia da situação de "nem guerra, nem paz", para forçá-lo a uma lógica de guerra, face à que existe (de uma certa maneira de forma "independente") na Unita de Jonas Savimbi. A (difícil) remobilização para a guerra começará então contra o inimigo militar que constitui a Unita de Savimbi, mas também contra a possibilidade que uma Unita política se dissidie e possa cristalizar o descontentamento social (daí a criação, com dissidentes ultraminoritários no seio dos deputados da Unita em Luanda, de uma "Unita Renovada", perfeitamente domesticada na velha lógica de cooptação-repressão do MPLA). Enquanto que os meios de intimidação do poder são reforçados e como este último em breve deixará de se preocupar com "formas" democráticas, o "povo" e a "sociedade civil" vão sendo mobilizados através de "patrões" (económicos e sociais), responsáveis da "sociedade civil" provenientes do poder ou por ele cooptados (coordenadores do partido, diversas organizações locais e milícias). o Presidente, com mais poder, servirse-á disso para reforçar ainda mais o seu controlo sobre o partido, utilizando, para fins próprios e na defesa dos interesses colectivos do poder, o conjunto de meios que lhe 
confere a posição que ganhou, entre os quais a neutralização sociopolítica das elites civis e a mobilização das redes privadas, civis, nacionais e internacionais construídas pelo seu clientelismo.

\section{BIBLIOGRAFIA}

Mabeko-Tali, J.-M. 1995, “La ‘chasse aux Zaïrois’ à Luanda”, Politique africaine, 57: 71-84.

Mabeko-Tali, J.-M. 1997, "L'interminable transition angolaise et les multiples dangers de l'incertitude politique", Lusotopie, IV: 87-103.

Messiant, C. 1994a, “Angola: le retour à la guerre ou l'inavouable faillite d'une intervention internationale”, L'Afrique politique 1994: 199-229.

Messiant, C. 1994b, “Angola, les voies de l'ethnisation et de la décomposition. I. De la guerre à la paix (1975-1991): le conflit armé, les interventions internationales et le peuple angolais", Lusotopie, I (1-2): 155-210.

Messiant, C. 1995a, “Angola. Les voies de l'ethnisation et de la décomposition. II. Transition à la démocratie ou marche à la guerre? L'épanouissement des deux 'partis armés' (mai 1991septembre 1992)", Lusotopie, II, 1995: 181-212.

Messiant, C. ed. 1995b, “L’Angola dans la guerre”, Politique africaine, 57.

\section{ANEXOS}

\section{Documento}

\section{Programação da "Semana da FESA" de 1998}

\section{Sábado, 22 de agosto}

Doações ao Leprosário de Funda.

Visita às pessoas removidas de Nambuangongo e Quibaxe e à "Cidadela das Crianças" de Caxito.

Maratona da Fesa.

\section{Domingo, 23 de agosto}

Visita às províncias de Huambo, Namibe e Cunene Atividades esportivas na Baía de Luanda e no Hotel Panorama (regata, travessia da Baía, esportes náuticos, paraquedismo, atividades de praia). Atividades esportivas no Estádio da Cidadela.

Segunda-feira, 24 de agosto

Visita à Província de Malange Inauguração de uma escola e doações de livros e brinquedos. Lançamento da terceira campanha nacional contra a poliomelite. 
Lançamento de um selo comemorativo.

Doações de bens e de vestuários aos sobas (chefes tradicionais).

Visita ao hospital regional e entrega de doações. Reunião-almoço para o avanço da

[construção] da Barragem de Capanda.

Retorno a Luanda.

Jantar de adesão e anúncio da criação de um fundo de solidariedade à luta contra a Aids.

Terça-feira, 25 de agosto

Luanda, Huambo, Namibe e Cunene

Inauguração de sistemas de teledifusão nas prisões de Bentiaba, Xangongo e Péu-Péu.

Entrega de doações e de equipamentos diversos. Abertura da segunda "Jornada

Técnico-Científica" (tema central: "O mar e seus recursos"), no Palácio do Congresso.

Diversas atividades esportivas.

Quarta-feira, 26 de agosto

Inauguração de escolas e da Avenida Lenin, em Luanda.

Inauguração do acesso à Internet nas escolas Primeiro de Maio e Ngola Zinga.

Quinta-feira, 27 de agosto

Inauguração da escola da Petrangol (Sambizanga) e da escola de Kikolo (Cacuaco).

Inauguração do Mercado Deolinda Rodrigues (Cazenga).

Inauguração da escola da 5e avenida (Cazenga). Melhorias do campo de áreas (Cazenga).

Inauguração da via de acesso Viana-Viana II. Atividades esportivas.

Cerimônia de registro público da sede definitiva da Fesa (escritura pública).

Entrega ao governo da província de Luanda do Jardim de Miramar e do Caminho da amizade da solidariedade "mestre Alioune Beye".

Cerimônia de lançamento da Fesa Magazine e apresentação da página eletrônica da Fesa.

Assinatura do protocolo tripartite para a reabilitação do Estádio dos Coqueiros.

Empossamento de novos curadores e de novos membros da Assembleia Geral da Fesa.

\section{Sexta-feira, 28 de agosto}

Final do campeonato escolar infantil. Demonstração de atividades esportivas por pessoas com deficiência.

Ginástica rítmica.

Encontro com crianças e idosos.

Apresentação simultânea de grupos musicais e de dança.

oferta de equipamentos para o basquete. Partilha do bolo de aniversário.

Sábado, 29 de agosto

Ato solene de entrega do título de Doutor honoris causa e do título de Comendador, pela Universidade Estadual do Rio de Janeiro, à Sua Excelência, engenheiro José Eduardo dos Santos, Patrono e Fundador da Fesa.

Encerramento da "Jornada Técnico-Científica". Espetáculo Fesa-Kutonoca (grupos musicais).

\section{Domingo, 30 de agosto}

Visitas aos trabalhos de restauração da Igreja de Nossa Senhora da Muxima.

Segunda-feira, 31 de agosto

Seminário sobre "O problema das minas e suas consequências". 
Exposição permanente de arte e artesanato no átrio do Palácio do Congresso.

Cerimônia de encerramento da Semana da Fesa. Jantar de arrecadação de fundos de amparo às vítimas das minas.

[Tradução do francês de Angela Lazagna (Campinas, Unicamp).]

\section{NOTAS}

1. Conferem os votos, agradecimentos, testemunhos de reconhecimento, panegíricos pagos por espaços publicitários na imprensa oficial ou gratuitos nessa mesma imprensa, rádios, o jornal do MPLA e as reacções numa parte da imprensa privada (Agora, Folha 8, Comércio actualidade sobretudo) em Agosto de 1997 e 1998.

2. Ver o dossier «L'Angola dans la guerre » (Messiant 1995b), e especialmente o artigo de A. Vines.

3. Criado no início da transição como orgão de "consulta" do Presidente da República, compreende, entre outros, "representantes" da sociedade civil, que são-no somente porque o Presidente assim o entende: é ele que os escolhe. Este orgão é um concentrado exemplar da política de cooptação do regime e particularmente do Presidente: faz parte dos privilégios do regime legal e não tem nenhum poder.

4. Para além das numerosas vantagens permanentes, todos recebem, por exemplo, um "subsídio de Natal de 25000 a 30000 dólares (o salário mínimo equivale a 4 dólares, que nem sequer dá para comprar uma grande lata de leite em pó; a grande maioria dos salários não ultrapassam 200 ou 300 dólares, os quadros pagos em dólares ganham, geralmente, entre 1000 e 2000 dólares... e Luanda, depois de Tóquio, é a cidade mais cara do mundo).

5. Pode simplesmente tratar-se agora de "envelopes" de várias dezenas ou centenas de milhares de dólares entregues a indivíduos, mas existem também outros: apoio gratuito e discreto a organizações amigas da sociedade civil (associações patronais, ordens profissionais, organizações sindicais, ONG, clubes diversos, organizações locais e de jovens); "indicação" amigável para um alto cargo numa sociedade pública ou privada, especialmente internacional, organismos internacionais ou ainda para a direcção de todos os novos orgãos de um Estado moderno (entre os quais um recente Instituto do Consumidor!), pagamento de consultores e assessores, etc.

6. Relativamente a este ponto, para além da imprensa privada e dos despachos da agência oficial ANGOP [Agência de Notícias Angola Press] dos anos 1997 et 1998, e especialmente dos meses de Agosto destes dois anos, ver sobretudo o sítio Internet da FESA (http://www.fesa.og.ao/).

\section{RESUMOS}

O surgimento, em 1996, da Fundação Eduardo dos Santos é resultado de um processo de privatização do Estado angolano. No entanto, a FESA também faz parte de uma estratégia presidencial que procura responder a múltiplos desafios: a não resolução do conflito armado, a exacerbação das rivalidades no seio do poder e a gravidade da crise social em virtude do esforço de guerra, da predação e da corrupção. 
L'apparition, en 1996, de la Fondation Eduardo dos Santos est l'aboutissement d'un processus de privatisation de l'État angolais. Mais la Fesa fait aussi partie d'une stratégie présidentielle qui tente de répondre à de multiples enjeux : la non-résolution du conflit armé, l'exacerbation des rivalités au sein du pouvoir et la gravité de la crise sociale, du fait de l'effort de guerre, de la prédation et de la corruption.

The founding, in 1996, of the Eduardo Dos Santos Foundation (FESA) marks the onset of the long process of the privatisation of the Angolan state. But the FESA is also part of a presidential strategy devised in response to certain dilemmas: the non-resolution of the armed conflict; the exacerbation of rivalries amongst the power elite; and the gravity of the social crisis caused by the war effort, predation, and corruption.

ÍNDICE

Palavras-chave: Angola, clientelismo, FESA, guerra civil, neopatrimonialismo

Keywords: Angola, civil war, clientelism, FESA, neopatrimonialism

Mots-clés: Angola, clientélisme, FESA, guerre civile, néopatrimonialisme

\section{AUTORES}

\section{CHRISTINE MESSIANT}

Centre d'études africaines, École des Hautes études en sciences sociales, Paris 